We hope that the building is an effective expression of our wish to provide for both group and individual activities; for openness of communication with due allowance for privacy; and for therapeutic, educational, and recreational activities (which are so closely interrelated).

We have attempted to plan and equip the various rooms so that they can be used for a variety of functions-for example, the hall has gymnastic and recreational equipment and a demountable stage, as well as facilities for films and lectures. The living areas, general-purpose room (girls), kitchen, and occupational therapy room will offer scope for domestic/household activities. The classrooms, quiet room, occupational therapy room, and general-purpose room (boys) have equipment for formal schoolroom work, technical and commercial studies, hobbies, craft work, and art.

There is within the unit no central or focal point, no room or area which is unequivocally the one part of the building around which other activities revolve, or in which the main activities take place. This is not owing to a failure to recognize the need for such a focal point. It was considered that having regard to the provisional treatment policy which had been evolved, no room or area should be given such special emphasis or prominence as to imply or suggest that it should be the most important part of the building. Just as it was considered that most of the rooms should be multipurpose, allowing flexibility of use and function by both patients and staff, so it was considered that both patients and stafi, in their working and living together, should be able to choose, depending on the needs at the particular time, which room(s) or area(s) to use for different purposes.

There is no central observation point, no central nurses station. Clearly, the absence of such a room reduces the range of observation which can be undertaken by any one nurse, thus placing a considerable responsibility on staff who are required to be aware of patients' movements within the building. But it was decided to accept the risks inherent in this rather than oreate a more institutional type of situation in which dormitories or sitting-rooms would be under observation by staff.
Experience may prove us mistaken, but it was our opinion that to have a focal point and central observation station for nursing staff might have value in terms of economy of staff, but would not be appropriate to the particular kind of therapeutic milieu which we hoped would develop.

\section{Some Problems}

The administration/consultation section contains both the department's headquarters and the consulting-rooms for the unit for adolescents. It was considered that these rooms, together with others in the unit itself, would offer sufficient facilities for individual and group therapy. This may prove to be unrealistic.

We wished the building to have a sense of light and space: only time will show whether the type and area of glass is a realistic compromise between this aim and the risk of breakage.

Wall surfaces have been finished in plaster, except in the hall, where grey facing bricks form the internal finish. We do not know whether these surfaces will.withstand the rough usage which may be expected.

Economy of installation and the existence of the main hospital's plant were the factors which decided that heating should be by low-pressure hot water supplied through a calorifier fed by steam from the main hospital's plant. Under-floor or ceiling heating might have reduced the disadvantages, both aesthetic and practical, of pipes and radiators.

\section{Conclusion}

This brief communication, which describes a new inpatient unit for the psychiatric treatment of adolescents, can indicate only some of the principles considered in its planning and suggest a few of the problems. It will be some years before these principles and the building which has been developed from them can be adequately tested. We hope that a later report on success and failure may be of some help to others planning similar units.

\title{
A Century of Asthma Deaths in Young People
}

\author{
F. E. SPEIZER,* M.D. ; R. DOLL, $\dagger$ M.D., F.R.C.P., F.R.S.
}

Brit. med.F., 1968, 3, 245-246

To appreciate properly the significance of the recent increase in the mortality attributed to asthma it is desirable, as Robbins (1968) points out, to examine its historical setting. This, according to Alexander (1963), cansists of a long period in which death in an attack was almost unknown, a period of 25 years in which death occurred with increasing frequency, and a period of a few years in which the annual number of deaths declined abruptly. In support of this conclusion he referred to an aphorism of William Osler that "the asthmatic pants into old age" and to extracts from nineteenth-century textbooks, case reports from the first half of the twentieth century, and crude mortality rates at all ages from the late $1930 \mathrm{~s}$ onwards.

Long-term comparisons of this type, however, are hazardous. In adult life asthma is commonly associated with other respiratory conditions, and the many changes in the rules for classifying causes of death, apart from possible changes in

\footnotetext{
* U.S. Public Health Service Special Fellow, Medical Research Council's Statistical Research Unit, London W.C.1. † Directo. Medical Research Council's Statistical Research Unit, London
W.C.1.
}

nomenclature and the accuracy of diagnosis, led Speizer, Doll, and Heaf (1968) to limit their comparison of mortality rates to ages 5 to 34 years and to a period of 15 years during which the sixth and seventh revisions of the international classification of causes of death had been used.

In the present note we have extended the comparison of mortality rates at these ages to include data over one hundred years. Because of the small numbers of deaths we have grouped the data and calculated average annual death rates for consecutive periods of five years. Data for the periods covered by the first and second world wars have been omitted because of the disturbance caused by the selection of young people into the armed Forces. Before 1911 deaths attributed to emphysema were intermittently coded with asthma, but this has been ignored. The number of deaths attributed to emphysema (when this was specified separately) was never more than $10 \%$ of the total attributed to both conditions at these ages; in all subsequent years emphysema was elassified separately. Since 1910 there have been several other major alterations of coding and classification procedure, and each decade saw the introduction of some change. The most important occurred in 1940, when 
a new method was introduced for selecting the underlying cause of death, and in 1958, when deaths certified as due to asthma with mention of bronchitis were removed from the asthma category.

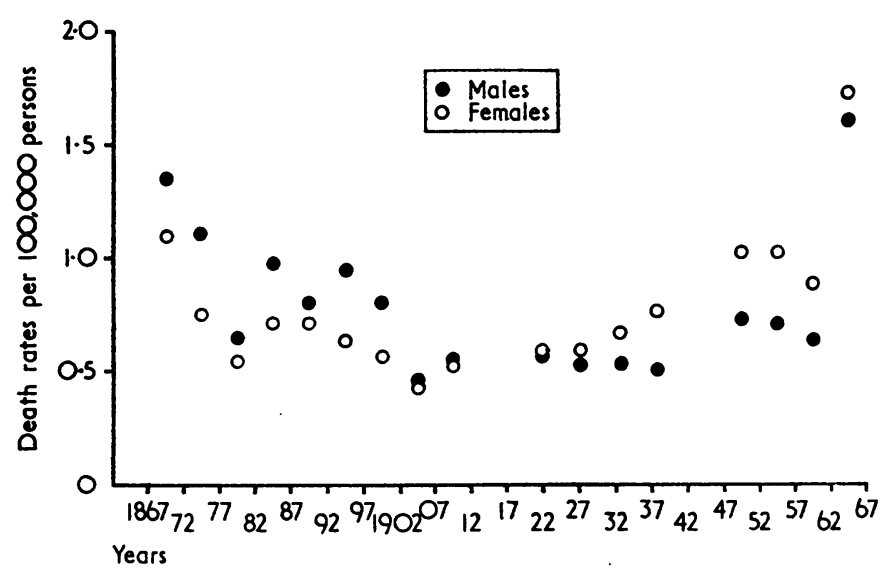

Death rates from asthma for England and Wales, 1867-1966, in miles and females aged $5-34$ years. Source: Annual Report of the Registrar General for the years 1867-1966.

\section{Results}

The results are summarized in the Chart. The outstanding feature is the stability of the rates between 1867 and 1961 . During this period the annual rate for males lay within the range 0.46 to 1.34 per 100,000 and for females within the range 0.43 and 1.10 per 100,000 . In the last half of the nineteenth century the rate in both sexes gradually declined, due possibly to greater precision in terminology. Subsequently the female rate increased again until 1952, while the male rate remained practically constant until 1937. These data, it will be noted, do not support the belief that death from asthma was unknown before 1930. Between 1947 and 1961 the change in mortality at ages 5 to 34 years was slight, despite the major change in the definition of the asthma category in 1958. The data provide at best only weak support for the hypothesis that the introduction of corticosteroids in 1952 appreciably reduced fatality.

Two other points are illustrated in the Chart. First, the death rate before the first world war was consistently higher in males than in females; subsequently the position was reversed. This can be explained if the female rate reflected most clearly the mortality from allergic asthma, while the male rate was deleteriously affected by the industrial conditions to which men were exposed in the second half of the nineteenth century. Secondly, the rates in 1962-6 were, in both sexes, the highest to have been recorded at any time in one hundred years.

Many factors account for the difference between Alexander's (1963) conclusion and the relative stability revealed by these data. Alexander did not distinguish between different age groups, and the trends in mortality at all ages are different from those in the age group 5 to 34 years. In our view, however, confusion between bronchitis in particular, other respiratory conditions in general, and asthma as a cause of death at old ages is likely to have been so great at some periods that the examination of trends in mortality at all ages will give a less accurate picture of the trends in mortality from asthma than those recorded at younger ages. Moreover, the reporting of individual deaths in the medical literature is highly selective and the frequency of such reports is likely to represent the state of medical interest rather than the frequency with which the event occurs.

The fact that authors of textbooks and leading physicians denied that deaths could occur due to asthma alone is not surprising. The recorded death rates at ages 5 to 34 years are of the order of 1 per 100,000 persons per year, and few doctors could be expected to see more than one such death in 20 to 30 years. Moreover, a background of a large group of patients who survive may lead to a false sense of security. All doctors will be concerned about the child with leukaemia, since death is almost inevitable. Few, however, will be concerned about the child with asthma, despite the fact that the death rate from asthma at ages 10 to 14 years is higher than that from leukaemia because most children survive and "pant into old age."

We certainly do not wish to suggest that national mortality rates are likely to provide an accurate estimate of the true mortality due to a particular disease over one hundred years. Death from asthma in young people, however, is usually surdden (Speizer, Doll, Heaf, and Strang, 1968) and the method of diagnosis of the condition has remained essentially unchanged. It would therefore seem to us that the long period of relative stability in the mortality rate before 1962 strengthens the belief that the recent abrupt increase in mortality is due to the introduction of some new factor rather than to a change in terminology or diagnostic fashion.

\section{REFERENCES}

Alexander, H. L. (1963). 7. Allergy, 34, 305.

Robbins, J. J. (1968). Brit. med. F., 2, 365.

Spcizer, F. E., Doll, R., and Heaf, P. (1968). Brit. med. \%., 1, 335. Speizer, F. E., Doll, R., Heaf, P., and Strang, L. B. (1968).' Brit. med. f., 1,339 .
A Special Correspondent writes: At the instigation of "Find Your Feet," an organization for the help of refugees throughout the world, a press conference was held at Rothamsted Agricultural and Experimental Station on 18 July to publicize the process devised by Dr. N. W. Pirie, F.R.S., for the extraction of protein from vegetable matter. Representatives of all sections of the press arrived in time to see Dr. Pirie's massive machine in full operation.

$\approx$ At one end the machine devoured masses of vegetable refuse, which chanced to be the pods, leaves and stalks of garden peas. Clover, lucerne, tares, or nettles would have done equally well. At the other end it delivered a protein concentrate, good food for the millions in underdeveloped countries. It worked by simple pressure of the juices out of the foliage, followed by the coagulation of the protein by heat. As a byproduct thin sheets of pressed fibre were obtained, a useful component for cattle food. One had the impression of being in a vegetable slaughter-house, with streams of bright-green fluid on the floor instead of blood.

Dr. Pirie first became interested in leaf protein in 1934. His concentrates were produced in bulk in 1940, and a unit for the further study of the problem was started in 1953. An extraction plant costs about $£ 8,000$, and the running costs are about $£ 10,000$ yearly. The chief practical problem is to find an adequate supply of lush, moist vegetable matter to keep the machine working for eight hours a day throughout a full working week. Dr. Pirie considers that in addition to casual supplies of foliage leafy crops will have to be specially grown. He visualizes each plant as being capable of providing supplementary protein for a town of some 60,000 inhabitants. Plants have already been operated successfully in New Guinea and Mysore. "Find Your Feet" hopes to raise funds for the production of two more plants, the first to be situated in East Africa. 